\title{
Prophylactic low-dose G-CSF in patients with breast cancer experiencing grade 4 neutropenia during their previous (neo-) adjuvant (F)EC-chemotherapy cycle: Results of a pilot study
}

\author{
E. Petru' ${ }^{1}$, S. Schwarz ${ }^{1,2}$, J. Haas ${ }^{1}$, V. Kolovetsiou ${ }^{1}$, N. Woltsche ${ }^{1}$, J. Klocker ${ }^{2}$ \\ 1. Department of Gynecology and Obstetrics, Medical University of Graz, Austria. 2. Department of Internal Medicine, \\ Klinikum Klagenfurt, Austria
}

Correspondence: E. Petru. Address: Department of Obstetrics and Gynecology, Medical University, Auenbruggerplatz 14, A-8036 Graz, Austria. Email: edgar.petru@medunigraz.at

Received: November 30, 2014 Accepted: December 21, 2014 Online Published: December 31, 2014

DOI : $10.5430 /$ jst.v4n4p47

URL: http://dx.doi.org/10.5430/jst.v4n4p47

\begin{abstract}
Grade 4 neutropenia is associated with an increased risk of infections. Low-dose lenograstim at 13 million units per day is commonly used in children undergoing cytotoxic chemotherapy. The present pilot study investigated the effect of prophylactic low-dose lenograstim (13 million units of lenograstim, GranozyteR, Sanofi-Aventis Pharma) in 20 patients with breast cancer who received (neo) adjuvant (F)EC (5-fluorouracil-epirubicin-cyclophosphamide) chemotherapy on days 3 to 10 of the chemotherapy cycle. All of them had experienced nadirs of absolute neutrophil counts (ANC) < $500 / \mathrm{mm}^{3}$ and white blood cells (WBC) $<1,000 / \mathrm{mm}^{3}$ during the preceding identical (F)EC chemotherapy cycle, respecttively. The primary endpoint of this study was the number of cycles with recurrent grade 4 neutropenia.

White blood cells, neutrophil granulocytes, hemoglobin, and platelets were recorded on days 1, 8, 15, and 22 of each cycle. Neutrophil counts and white blood cells remained stable over time $(p>.05)$. Grade 4 neutropenia occurred in $4 \%$ of lenograstim-supported cycles only. Antibiotics were necessary in $4 \%$ of cycles only. Grade 1 or 2 bone pain was recorded in $14 \%$. In conclusion, an economic regimen of prophylactic low-dose lenograstim, administered at 13 million units per day over 8 days, has been demonstrated to maintain neutrophil levels above the critical level and thus to prevent grade 4 neutropenia. Trials comparing this regimen with pegylated G-CSF seem warranted.
\end{abstract}

\section{Key words}

Granulocyte colony-stimulating factors, Neutropenia, Breast cancer, Anthracycline-based chemotherapy, Lenograstim, Low-dose granulocyte colony stimulating factors

\section{I ntroduction}

Grade 4 neutropenia is associated with an increased risk of infections. Febrile neutropenia develops in up to 8\% of patients with breast cancer during conventional chemotherapy ${ }^{[1-3]}$ and is responsible for a mortality rate of up to $7 \%{ }^{[4,5]}$. Patients receiving (F)EC chemotherapy for breast cancer carry a risk of about $5 \%$ for developing febrile neutropenia ${ }^{[1-3]}$. 
Standard doses of prophylactic G-CSF include filgrastim at 30 or 48 million units or lenograstim 34 million units administered for 5 to 8 days usually starting on day 3 of each cycle. Over the past decade, pegylated filgrastim formulations have been widely integrated in the clinical routine. They are convenient since they have to be administered only once every cycle and do not cause more side effects than daily administrations of G-CSF. However, particularly the use of PEG-filgrastim or LIPEG-filgrastim is considerably more costly than daily administrations of G-CSF. Thus, alternate administration schedules of G-CSF administration seem warranted.

Low-dose lenograstim at 13 million units per day is commonly used in children undergoing cytotoxic chemotherapy. The authors have found this dosage to be well tolerated and active in selected adult patients in our hospital who had previously experienced significant bone pain due to conventional G-CSF treatment regimens. Prolonged low-dose G-CSF was considered a feasible alternative for patients experiencing significant neutropenia following anthracycline-based chemotherapy.

The present pilot study investigated the effect of prophylactic low-dose lenograstim administered over eight days to 20 consecutive patients with breast cancer who received (neo) adjuvant (F) EC (5-fluorouracil-epirubicin-cyclophosphamide) chemotherapy. All of them had experienced a nadir of absolute neutrophil counts (ANC) $<500 / \mathrm{mm}^{3}$ and white blood cells $(\mathrm{WBC})<1,000 / \mathrm{mm}^{3}$ during the preceding identical (F)EC chemotherapy cycle, respectively.

The primary endpoint of this study was the number of cycles with recurrent grade 4 neutropenia at nadir. Secondary endpoints were the number of infections and the toxicities caused by low-dose lenograstim.

\section{Material and methods}

During nine months, a total of 20 consecutive patients with histologically verified primary breast cancer who had experienced a nadir of grade 4 neutropenia and leucopenia during their preceding (neo-) adjuvant chemotherapy cycle with 5-fluorouracil-epirubicin-cyclophosphamide (FEC: $500 \mathrm{mg} / \mathrm{m}^{2} ; 75 \mathrm{mg} / \mathrm{m}^{2} ; 500 \mathrm{mg} / \mathrm{m}^{2}$ or EC: $60-90 \mathrm{mg} / \mathrm{m}^{2} ; 600 \mathrm{mg} / \mathrm{m}^{2}$ ), respectively, were recruited for this pilot study. Patients who experienced febrile neutropenia during the previous cycle were not included.

All patients had given informed consent for study participation. They were prophylactically treated with 13 million units of G-CSF (lenograstim, GranozyteR, Sanofi-Aventis Pharma) administered s.c. daily from day 3 to day 10 during the subsequent (F)EC cycle(s). Study medication was provided by Sanofi Aventis. Patients were instructed to use paracetamol $500 \mathrm{mg}$ for up to three times daily in the case of bone pain.

White blood cells, neutrophil granulocytes, hemoglobin, and platelets were checked on day 1, 8, 15, and 22 of each cycle. At each visit, side effects of chemotherapy with special reference to febrile episodes, infections, and bone pain were recorded.

The Pearson chi-square test was used to test statistical differences between groups.

\section{Results}

Pretreatment characteristics of the 20 study patients enrolled are detailed in Table 1.

One patient received erythropoietin also. Efficacy of prophylactic low-dose lenograstim therapy is shown in Table 2. Detailed laboratory values on days 1, 8, 15, and 22 are depicted in Figures 1 to 4 . While neutrophil counts and white blood cells remained stable over time ( $p>.05)$, significant differences were found in haemoglobin values $(p=.000)$ and platelet counts $(p=.000)$ over time. 
Table 1. Pretreatment characteristics of the 20 female breast cancer patients who had developed both grade 4 neutropenia and leukopenia during their preceding (neo)adjuvant (F)EC chemotherapy cycle and who were prophylactically treated with low-dose lenograstim in the subsequent identical chemotherapy cycle/s

\begin{tabular}{|c|c|}
\hline Variables & No. of patients (\%) \\
\hline Median age, years & 52 (range $26-74$ ) \\
\hline Age $>65$ years & $7(35 \%)$ \\
\hline Karnofsky performance status $<80$ & $4(20 \%)$ \\
\hline Body weight; kg; median & 68 (range $51-85$ ) \\
\hline Previous radiotherapy* & $3(15 \%)$ \\
\hline Previous chemotherapy for another primary cancer* & $2(10 \%)$ \\
\hline \multicolumn{2}{|l|}{ Preceding type of chemotherapy before study inclusion } \\
\hline Epirubicin/cyclophosphamide (60-90/600) every 3 weeks & $17(85 \%)$ \\
\hline 5-Fluoruracil/epirubicin/cyclophosphamide (500/75/500) every 3 weeks & $3(15 \%)$ \\
\hline \multicolumn{2}{|l|}{ No. of the preceding cycle at which grade 4 neutropenia and leukopenia was recorded } \\
\hline Cycle 1 & $17(85 \%)$ \\
\hline Cycle 2 & $3(15 \%)$ \\
\hline \multicolumn{2}{|c|}{ Level of nadir of absolute neutrophil count (ANC) during the preceding chemotherapy cycle } \\
\hline $250-499 / \mathrm{mm}^{3}$ & $10(50 \%)$ \\
\hline $100-249 / \mathrm{mm}^{3}$ & $8(40 \%)$ \\
\hline$<100 / \mathrm{mm}^{3}$ & $2(10 \%)$ \\
\hline \multicolumn{2}{|l|}{ Neutropenia-associated infection recording during the previous chemotherapy cycle } \\
\hline Yes** & $8(40 \%)$ \\
\hline None & $12(60 \%)$ \\
\hline
\end{tabular}

* Previous radiotherapy to the contralateral breast.

** Grade 2 infections observed were herpes zoster $(n=1)$, stomatitis $(n=1)$, and urinary tract infection $(n=1)$. Grade 1 infections were herpes simplex ( $n=1)$ and stomatitis ( $\mathrm{n}=3$ ). No patient experienced febrile neutropenia.

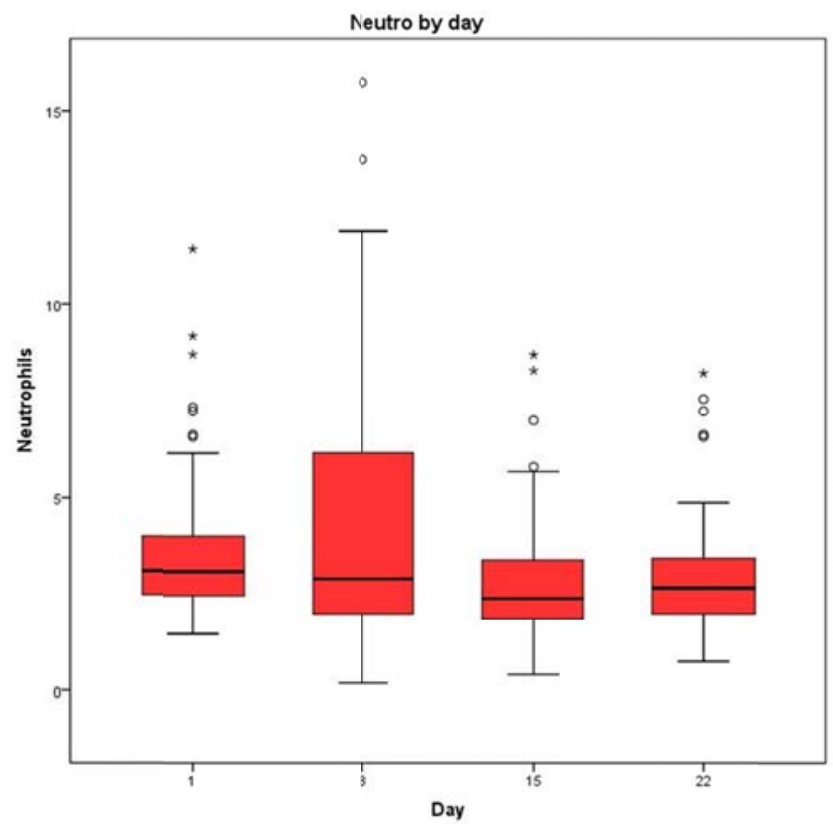

Figure 1. Neutrophil counts (G/l) on days 1, 8, 15 and 22 in patients undergoing low-dose prophylactic lenograstim therapy following (F) EC chemotherapy for early breast cancer. Bars represent the means + respective ranges of neutrophil cells.

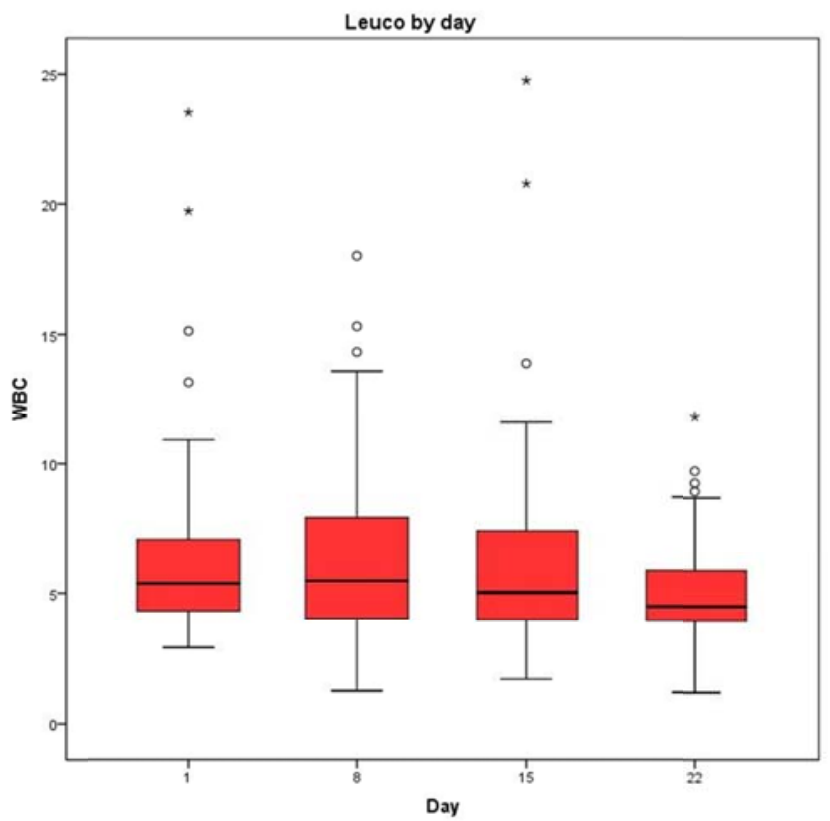

Figure 2. White blood cells (G/l) on days 1, 8, 15 and 22 in patients undergoing low-dose prophylactic lenograstim therapy following (F)EC chemotherapy for early breast cancer. Bars represent the means + respective ranges of white blood cells. 


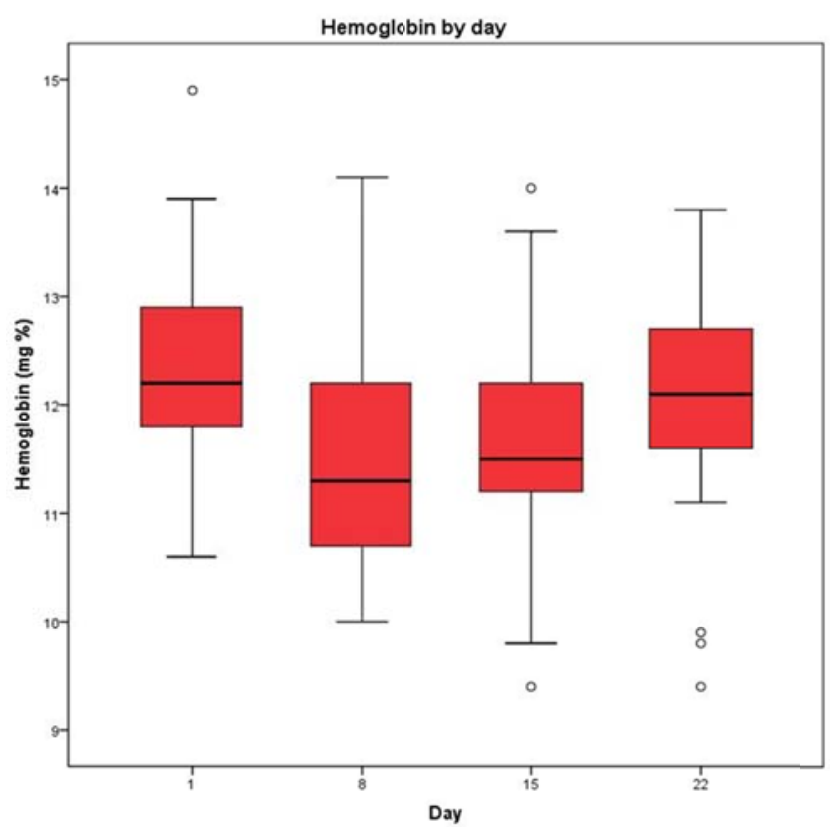

Figure 3. Hemoglobin values (g/dl) on days 1, 8, 15 and 22 in patients undergoing low-dose prophylactic lenograstim therapy following (F)EC chemotherapy for early breast cancer. Bars represent the means + respective ranges of hemoglobin values.

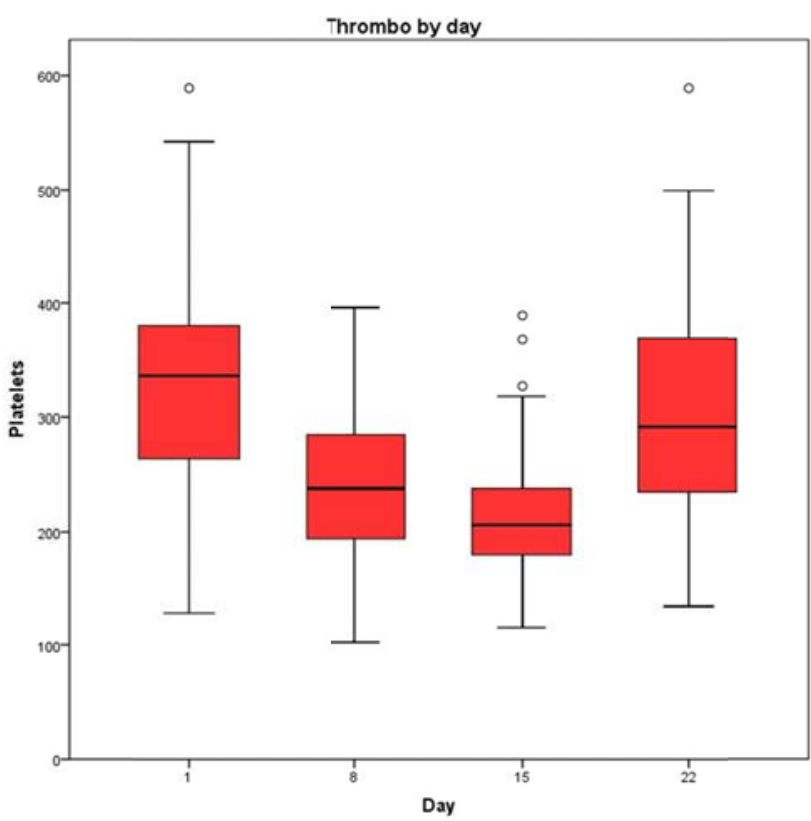

Figure 4. Platelets (G/l) on days 1, 8, 15 and 22 in patients undergoing low-dose prophylactic lenograstim therapy following (F)EC chemotherapy for early breast cancer. Bars represent the means + respective ranges of platelets.

Table 2. Efficacy of prophylactic low-dose lenograstim in the 20 breast cancer patients who had developed grade 4 neutropenia and leukopenia during their preceding adjuvant (F)EC chemotherapy cycle in the subsequent identical chemotherapy cycle(s)

\begin{tabular}{ll}
\hline Variables & Total no. of cycles (n = 49) \\
\hline $\begin{array}{l}\text { No. of cycles of low-dose prophylactic lenograstim per patient } \\
\text { within the pilot study }\end{array}$ & $20(41 \%)$ \\
1 cycle & $15(31 \%)$ \\
2 cycles & $10(6 \%)$ \\
3 cycles & $3(1 \%)$ \\
4 cycles & $1(0.2 \%)$ \\
5 cycles & $2(4 \%)^{*}$ \\
Grade 4 neutropenia $\left(<500 / \mathrm{mm}^{3}\right)$ & $5(10 \%)^{* *}$ \\
Grade 3 neutropenia $\left(<1,000 / \mathrm{mm}^{3}\right)$ & $1(0.2 \%)$ \\
Delay of subsequent chemotherapy due to neutropenia & $3(6 \%)$ \\
Leukocytosis $>20,000 / \mathrm{mm}^{3} * * *$ & $3(6 \%)$ \\
Neutrophil counts $>10,000 / \mathrm{mm}^{3 * * *}$ & \\
Infections & $1(2 \%)$ \\
$\quad$ Urinary tract infection & $1(2 \%)$ \\
$\quad$ Grade 2 stomatitis & $1(2 \%)$ \\
$\quad$ Grade 1 stomatitis & \\
Toxicites potentially related to G-CSF prophylaxis & $7(14 \%)$ \\
Grade 1 to 2 bone pain & $1(2 \%)$ \\
Phlebothrombosis of the left upper extremity**** & $1(2 \%)$ \\
Thrombophlebitis of an upper extremity &
\end{tabular}

* Development on day $8\left(190 / \mathrm{mm}^{3}\right)$ by one patient and on day $15\left(410 / \mathrm{mm}^{3}\right)$ by another patient.

** Development on day 8 by one patient, on day 15 by three patients, and on day 22 by another patient, respectively.

*** All on day 8 .

**** This patient had a infraclavicularly implanted intravenous port a cath system. 
The median number of chemotherapy cycles after the initiation of prophylactic G-CSF was 2 (range 1-5) depending on the time point of study inclusion. No significant differences in blood counts were observed between patients who underwent one cycle with prophylactic lenograstim only as compared to those with $>2$ supportive cycles.

Infections and side effects observed during lenograstim prophylaxis are detailed in Table 2.

\section{Discussion}

In this pilot study, the feasibility, efficacy, and safety of prophylactic low-dose lenograstim administered daily subcutaneously from day 3 to day 10 in 20 patients undergoing (F)EC chemotherapy has been demonstrated. As the inclusion criterion, all patients had previously developed non-febrile grade 4 neutropenia and leukopenia during their last identical (F)EC cycle. As the main result, the neutrophil and white blood cell counts remained almost stable during the course of the cycles (see Figures 1 and 2).

G-CSF are the cornerstone in the prevention of chemotherapy-induced neutropenia ${ }^{[1-3]}$. G-CSF significantly reduces infectious mortality ${ }^{[4,5]}$.

Many oncologic centers use prophylactic G-CSF in patients experiencing neutropenia $<500 / \mathrm{mm}^{3}$ in the preceding chemotherapy cycle. The authors could not find detailed data about its incidence in the literature. From the personal experience, the incidence may lie between $10 \%$ to 15\% of (F)EC cycles. Usually, after development of grade 4 afebrile neutropenia in the previous chemotherapy cycle, prophylactic filgrastim regimens at 30 or 48 million units daily or PEG-filgrastim/LIPEG-filgrastim at $6 \mathrm{mg}$ on day 2 are used. Although such an approach is effective, alternative G-CSF formulations seem warranted.

The administration of the G-CSF lenograstim at a lower dosage over eight days was considered to fulfill both the criteria for sufficient efficacy and high tolerability ${ }^{[6-10]}$. This regimen was supposed to lead to reduced bone pain as compared to conventional regimens ${ }^{[11]}$.

In the present study, the median neutrophil and absolute neutrophil counts remained stable over the cycles' duration. In a randomized study of $6 \mathrm{mg}$ PEG-filgrastim versus $5 \mu \mathrm{g} / \mathrm{kg}$ filgrastim, the median ANC showed rapid increases up to $31,000 / \mathrm{mm}^{3}$ and $45,000 / \mathrm{mm}^{3}$ on day 4 , respectively ${ }^{[4]}$. The authors hypothesized that 13 million units of lenograstim used in this study might reduce the risk for ANC elevations above $30,000 / \mathrm{mm}^{3}$. Indeed, leucocytosis above $20,000 / \mathrm{mm}^{3}$ was observed in $6 \%$ of cycles only. Low-dose lenograstim might hypothetically reduce the risk for the development of second malignancies including myelodysplastic syndrome ${ }^{[12]}$. Bone pain was reported in $14 \%$ of cycles only. This percentage is considerably lower than that reported following PEG-filgrastim ${ }^{[11]}$.

The use of low-dose G-CSF therapy has significant economic implications. PEG-filgrastim formulations cost around 1500 to 1700 EUR per application, while eight doses of low-dose lenograstim - as used in the present study - cost about 560 EUR only, respectively.

During the 49 cycles with lenograstim support in the present study, only two episodes of ANC values $<500 / \mathrm{mm}^{3}$ (grade 4 neutropenia) were observed (see Table 2). Only one urinary tract infection occurred which was treated with oral ciprofloxacin. Two further patients developed grade 1 and 2 stomatitis, respectively. Both patients received symptomatic local treatment and one of them amoxicillin/clavulanic acid in addition.

Although the low-dose G-CSF regimen used in this pilot study was considerably active with regard to maintaining levels of neutrophils and white blood cells, the necessity to administer the drug at 8 subsequent days represents a relevant disadvantage particularly when compared to single prophylactic administration of PEG-filgrastim on day 2. 
In conclusion, conventional G-CSF is a cornerstone in the prophylaxis of febrile neutropenia but associated with significant costs ${ }^{[13]}$. Alternative prophylactic G-CSF regimens seem warranted. In the present pilot study, low-dose lenograstim demonstrated efficacy in maintaining neutrophils and white blood cell counts at a safe level. Infections were rare. This low-dose regimen should be confirmed in larger trials.

\section{References}

[1] Aapro MS, Cameron DA, Pettengell R, et al. EORTC guidelines for the use of granulocyte-colony stimulating factors to reduce the incidence of chemotherapy-induced febrile neutropenia in adult patients with lymphomas and solid tumours. Eur J Cancer. 2006; 42: 2433-2453. PMid:16750358 http://dx.doi.org/10.1016/j.ejca.2006.05.002

[2] Aapro MS, Bohlius J, Cameron D, et al. 2010 update of EORTC guidelines for the use of granulocyte colony stimulating factors to reduce the incidence of chemotherapy-induced febrile neutropenia in adult patients with lymphoproliferative disorders and solid tumours. Eur J Cancer. 2011; 47: 8-32. PMid:21095116 http://dx.doi.org/10.1016/j.ejca.2010.10.013

[3] Crawford J, Allen J, Armitage J, et al. for the National Comprehensive Cancer Network. Myeloid Growth Factors. J Natl Compreh Canc Network. 2011; 9: 914-929. PMid:21900221

[4] Smith TJ, Khatcheressian J, Lyman G, et al. 2006 update of recommendations for the use of white blood cell growth factors: an evidence-based clinical practice guideline. J Clin Oncol. 2006; 24: 3187-3205. PMid:16682719 http://dx.doi.org/10.1200/JCO.2006.06.4451

[5] Clark O, Lyman G, Castro A, Clark L, Djulbegovic I. Colony-stimulating factors for chemotherapy-induced febrile neutropenia: a meta-analysis of randomized controlled trials. J Clin Oncol. 2005; 23: 4198-4212. PMid:15961767 http://dx.doi.org/10.1200/JCO.2005.05.645

[6] Lyman G, Kuderer, N, Crawford J, et al. Risk of mortality in patients with cancer who experience febrile neutropenia. Cancer. 2010; 116: 5555-5563. PMid:20715160 http://dx.doi.org/10.1002/cncr.25332

[7] Lyman G. Balancing the benefits and costs of colony-stimulating factors: A current perspective. Semin Oncol. 2003; 30 (Suppl 13): 10-17. http://dx.doi.org/10.1016/S0093-7754(03)00312-9

[8] Papaldo P, Lopez M, Marolla P, et al. Impact of five prophylactic filgrastim schedules on hematologic toxicity in early breast cancer patients treated with epirubicin and cyclophosphamide. J Clin Oncol. 2005; 23: 6908-6918. PMid:16129844 http://dx.doi.org/10.1200/JCO.2005.03.099

[9] Toner G, Shapiro J, Laidlow C, et al. Low-dose versus standard-dose lenograstim prophylaxis after chemotherapy: A randomized, crossover comparison. J Clin Oncol. 1998; 16: 3874-3879. PMid:9850033

[10] Bartelt M, Harman S, Lower E. Halved pegfilgrastim doses in adjuvant breast cancer patients associated with similar efficacy but reduced toxicity. Breast Cancer Res Treat. 2007; 106 (Suppl 1): S105-S106

[11] Sierra J, Harms R, Mo M, Vogel C. Evaluation of reported bone pain in patients receiving chemotherapy in pegfilgrastim clinical trials. J Clin Oncol. 2009; 27 (20 Suppl): 15S (abstr 9621)

[12] Lyman G, Dale D, Wolff D, Culakova E, et al. Acute myeloid leukemia or myelodysplastic syndrome in randomized controlled clinical trials of cancer chemotherapy with granulocyte colony-stimulating factor: A systematic review. J Clin Oncol. 2010; 28: 2914-2924. PMid:20385991 http://dx.doi.org/10.1200/JCO.2009.25.8723

[13] Von Minckwitz G, Kummel S, DuBois A, et al. Pegfilgrastim +/- ciprofloxacin for primary prophylaxis with TAC (docetaxel/ doxorubicin/cyclophosphamide) chemotherapy for breast cancer. Results from the GEPARTRIO study. Ann Oncol. 2008; 19: 292-298. PMid:17846019 http://dx.doi.org/10.1093/annonc/mdm438 